\title{
How Do Microtubule Dynamics Relate to the Hallmarks of Learning and Memory?
}

\author{
ㅈonstantin Kaganovsky* and Cosmos Yuqi Wang* \\ Stanford University, Graduate Program in Neuroscience, Stanford, California 94305-5420 \\ Review of Martel et al.
}

It is well known that the hippocampus plays an important role in learning and memory. In the fear conditioning procedure, whereas the amygdala is central to tone-shock association, the hippocampus is critical for contextual associations (Calandreau et al., 2005; Trifilieff et al., 2006). In particular, the dentate gyrus is critical for contextual memory formation and retrieval (Drew et al., 2013; Clemenson et al., 2015). Numerous molecular and cellular mechanisms underlie the role of the dentate gyrus in learning and memory. These include NMDA receptor activation, spinogenesis, and neurogenesis (Tsien et al., 1996; Hamilton et al., 2012; Drew et al., 2013; Kempermann et al., 2015). Notably, these processes may be linked: NMDA receptor activation in neural progenitor cells promotes neurogenesis (Deisseroth et al., 2004), and the survival of these newly generated neurons is competitively regulated by their levels of NMDA receptor activation as compared with the surrounding mature neurons. (Tashiro et al., 2006). Moreover, NMDA activation and the downstream activation of the transcription factor CREB contribute to maturation and

Received March 19, 2016; revised April 25, 2016; accepted April 26, 2016. This work was supported by Stanford Graduate Fellowships in Science and Engineering (K.K. and C.Y.W.). We thank Dr. Aaron Gitler for insightful comments.

The authors declare no competing financial interests.

${ }^{*}$ K.K. and C.Y.W. contributed equally to this work.

Correspondence should be addressed to either Konstantin Kaganovsky or Cosmos Yuqi Wang, Stanford University School of Medicine, 1215 Welch Road, Modular B, \#42, Stanford, CA 94305-5420, E-mail: kkaganovsky@gmail.com or cosmosyw@stanford.edu.

DOI:10.1523/JNEUROSCI.0920-16.2016

Copyright $\odot 2016$ the authors $\quad 0270-6474 / 16 / 365911-03 \$ 15.00 / 0$ spinogenesis in newborn neurons (Silva et al., 1998; Vadodaria and Gage, 2014).

Microtubules play an essential role in many cellular processes, including transporting mRNA, organelles, and proteins (including NMDA receptors), and thus it is not surprising that proteins that regulate microtubule dynamics play critical roles in spine plasticity, neurogenesis, and memory formation. One such protein is a cytosolic phosphoprotein, stathmin, whose unphosphorylated form binds to tubulin heterodimers and prevents their polymerization. (Belmont and Mitchison, 1996; Shumyatsky et al., 2005; Uchida et al., 2014). When phosphorylated, stathmin releases tubulin, allowing microtubule formation (Belmont and Mitchison, 1996). Consistent with a role in memory, stathmin is expressed in neurons in the cortex, hippocampus, and amygdala, with little expression in glia (Shumyatsky et al., 2005). Mice lacking stathmin exhibit impaired longterm potentiation (LTP) at cortico- and thamalo-amygdala synapses, as well as impaired amygdala-dependent fear memory (Shumyatsky et al., 2005). However, these stathmin knock-out mice show normal hippocampus-dependent spatial memory, possibly because of low expression of endogenous stathmin in hippocampus (Shumyatsky et al., 2005). In addition, a nonphosphorylatable form of stathmin, Stat4A, (Kuntziger et al., 2001), has a very high affinity for tubulin heterodimers and destabilizes microtubules. Given the LTP impairments of stathmin knock-out mice, it is interesting that Stat4A knock-in mice ex- hibit normal amygdala-dependent fear memory but have impaired hippocampusdependent LTP and memory formation. The latter impairment involves reduced synaptic targeting of GluA2 after learning (Uchida et al., 2014).

In a recent article in The Journal of Neuroscience, Martel et al. (2016) proposed a mechanism that links NMDA receptor subunit trafficking, neurogenesis, spinogenesis, and specific aspects of learning to microtubule dynamics. The authors used an inducible bitransgenic mouse in which Stat $4 A$ was expressed only in the absence of the antibiotic doxycycline (Kuntziger et al., 2001; Uchida et al., 2014). Importantly, Stat4A expression was restricted to neurons in the dentate gyrus, lateral amygdala, and anterior cingulate cortex (Martel et al., 2016, their Fig. 2). The authors focused on effects in the dentate gyrus because it is a major site of adult neurogenesis (Kempermann et al., 2015).

Critically, Martel et al. (2016) demonstrated that Stat4A-expressing and control dentate gyrus had equivalent numbers of DCX + neurons, neurons that presumably have the ability to proliferate (Martel et al., 2016, their Fig. 4B). However, using BrdU staining to label actively dividing neurons, the authors found that proliferation into the subgranular zone, survival in dentate gyrus, and dendritic complexity of immature $(\mathrm{DCX}+)$ neurons were reduced in Stat4Aexpressing mice (Martel et al., 2016, their Figs. $3 D, E, 4 C, D)$. These data support the idea that the decrease in neurogenesis was not likely a result of depleted reserves of 


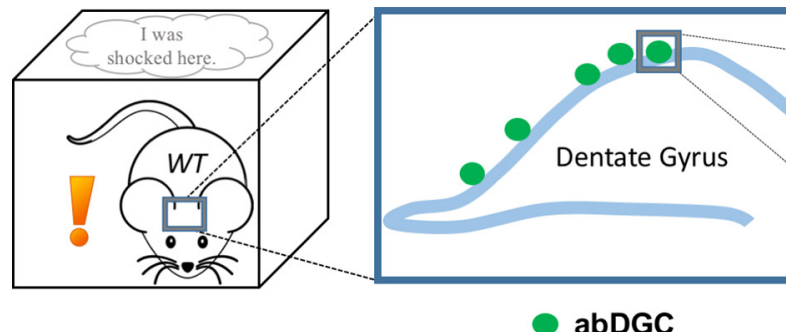

abDGC

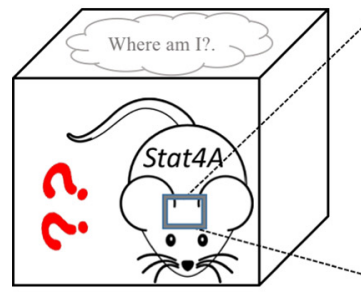

Deficit in fear conditioning

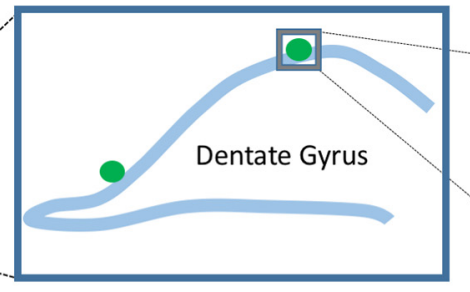

Reduced neurogenesis

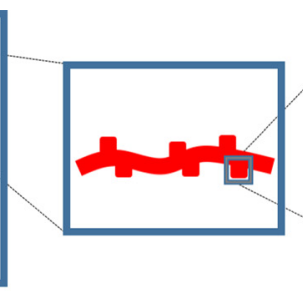

- dendritic spines

$$
\text { - dendritic spines }
$$
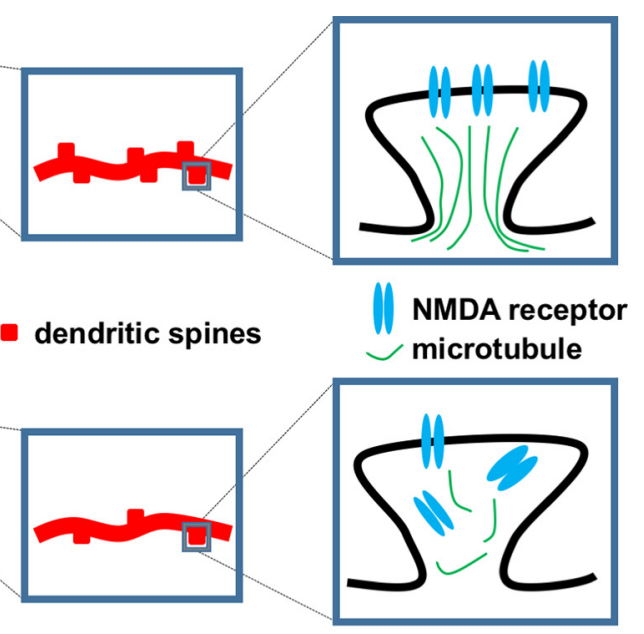

Reduced spinogenesis

\section{Destabilized microtubule, reduced synaptic NMDA receptors}

Figure 1. A summary of Martel et al. (2016) findings published in The Journal of Neuroscience. Mice that overexpress a constitutively active form of stathmin, Stat4A, exhibit changes from the molecular to behavioral levels. Stat4a expression destabilizes microtubules, therefore reducing synaptic targeting of NMDA receptors, spinogenesis, and neurogenesis. These mice also exhibit learning and memory impairments in contextual fear conditioning, NMDA-dependent memory tasks, and memory discrimination tasks. WT, Wild-type mouse; abDGC, adult born dentate granule cells.

neurons with the ability to proliferate but rather a decrease in the ability of these neurons to survive, proliferate, and mature.

Given that NMDA receptor signaling modulates aspects of neurogenesis (Deisseroth et al., 2004; Tashiro et al., 2006), Martel et al. (2016) tested whether Stat $4 A$ knock-in alters the composition of NMDA receptor subtypes. Compared with controls, Stat4Aexpressing mice exhibited decreased GluN2A and GluN2B expression in the microtubule and synaptosomal fractions but no differences in whole-cell extracts, consistent with a role of microtubule dynamics in regulating NMDA receptor subunit transport to synaptic sites, but not in regulating subunit expression. Finally, the authors showed that Stat 4 A decreased CREBdependent gene transcription. Importantly, doxycycline administration, effectively suppressing Stat $4 A$ transgene expression, in a separate group of mice reversed all of the alterations mentioned above.

Martel et al. (2016) verified that the molecular and cellular phenotypes produced by Stat $4 A$ expression were behaviorally relevant by demonstrating deficits in hippocampus-, NMDA-, and neurogenesisdependent fear conditioning in Stat4Aexpressing mice (Fig. 1). More specifically, these transgenic mice exhibited normal cued fear memory (amygdala-dependent) but impaired contextual fear memory (dorsal hippocampus and NMDA receptordependent). In addition, hippocampusdependent, NMDA-independent memory was spared in these mice (Hardt et al., 2009). However, the mice were unable to learn to discriminate two similar contexts: a deficit in pattern separation that critically depends on neurogenesis. Importantly, direct infusion of doxycycline into the dentate gyrus, but not into the lateral amygdala, rescued the impaired contextual discrimination (Martel et al., 2016, their Fig. 8).

One important consideration for interpreting these data are the nonphysiological role of Stat4A. Martel et al.'s (2016) Stat4A overexpression effectively reduced microtubule dynamics while leaving endogenous levels of stathmin unchanged. Therefore, the data reflect the role of microtubule dynamics in learning and memory rather than the role of stathmin per se. Under normal conditions, the four phosphorylation sites on stathmin are differentially regulated; for example, the level of stathmin phosphorylation increases on serine 16 and decreases on serines 25 and 28 after fear conditioning (Uchida et al., 2014). It would be interesting to explore the phosphorylation dynamics of stathmin during proliferation and survival of adult born dentate granule cells, dynamics that are surely regulated by a multitude of kinases and phosphatases in response to intracellular signals.

Martel et al.'s (2016) discoveries prompt further investigation into the molecules causally linking microtubule dynamics to learning and memory. In particular, Martel et al. (2016) show that
Stat $4 A$ knock-in leads to decreased synaptosomal GluN2A and GluN2B expression (without affecting the obligatory GluN1 subunit; Martel et al., 2016, their Fig. 10); however, it is known that GluN2B deletion in adult born dentate granule cells impairs contextual fear discrimination independent of neuronal proliferation and survival (Kheirbek et al., 2012). Therefore, Stat $4 A$ knock-in affects proliferation and survival through GluN2A or a mechanism independent of NMDA receptors, such as through cell-cycle arrest (Cassimeris, 2002). Furthermore, microtubule dynamics could regulate a multitude of downstream molecules. Rescue experiments of neurogenesis and of specific GluN2 subunits in adult born dentate granule cells in the same bitransgenic Stat $4 \mathrm{~A}$ mouse line used by Martel et al. (2016) could further elucidate the precise mechanisms by which Stat4A expression leads to the distinct cellular and learning phenotypes demonstrated by Martel et al. (2016).

The authors showed that Stat4A knock-in mice exhibit learning deficits associated with hippocampus rather than amygdala (Uchida et al., 2014; Martel et al., 2016). But global stathmin knock-out mice have impaired amygdala-associated memory with spared hippocampus-associated memory (Shumyatsky et al., 2005). These seemingly contradictory results may be due to differences between the gene expression profile of amygdala and hippocampus. 
Hence, detailed analysis of brain-regionspecific differences in protein expression and baseline kinase activity may supplement our understanding, complementing the importance of differential anatomical connectivity, of the mechanisms by which a given brain region (ie, amygdala, hippocampus, etc) specializes in a specific form of learning.

Martel et al. (2016) demonstrated a role for stathmin-mediated microtubule dynamics in GluN2A and GluN2B synaptic expression, neurogenesis, spinogenesis, and specific forms of fear conditioning (Fig. 1). Critically, suppressing the Stat $4 A$ transgene in the dorsal hippocampus rescues fear conditioning deficits. Moreover, the use of behavioral procedures to support the hippocampal, NMDA, and neurogenesis dependent nature of the learning deficits, and therefore molecular manipulation, can serve as a model for future phenotypical characterizations.

\section{References}

Belmont LD, Mitchison TJ (1996) Identification of a protein that interacts with tubulin dimers and increases the catastrophe rate of microtubules. Cell 84:623-631. CrossRef Medline

Calandreau L, Desmedt A, Decorte L, Jaffard R (2005) A different recruitment of the lateral and basolateral amygdala promotes contextual or elemental conditioned association in Pavlovian fear conditioning. Learn Mem 12: 383-388. CrossRef Medline

Cassimeris L (2002) The oncoprotein 18/stathmin family of microtubule destabilizers. Curr Opin Cell Biol 14:18-24. CrossRef Medline

Clemenson GD, Lee SW, Deng W, Barrera VR, Iwamoto KS, Fanselow MS, Gage FH (2015) Enrichment rescues contextual discrimination deficit associated with immediate shock. Hippocampus 25:385-392. CrossRef Medline

Deisseroth K, Singla S, Toda H, Monje M, Palmer TD, Malenka RC (2004) Excitation-neurogenesis coupling in adult neural stem/progenitor cells. Neuron 42:535-552. CrossRef Medline

Drew LJ, Fusi S, Hen R (2013) Adult neurogenesis in the mammalian hippocampus: why the dentate gyrus? Learn Mem 20:710-729. CrossRef Medline

Hamilton AM, Oh WC, Vega-Ramirez H, Stein IS, Hell JW, Patrick GN, Zito K (2012) Activity-dependent growth of new dendritic spines is regulated by the proteasome. Neuron 74:1023-1030. CrossRef Medline

Hardt O, Wang SH, Nader K (2009) Storage or retrieval deficit: the yin and yang of amnesia. Learn Mem 16:224-230. CrossRef Medline

Kempermann G, Song H, Gage FH (2015) Neurogenesis in the adult hippocampus. Cold Spring Harb Perspect Biol 7:a018812. CrossRef Medline

Kheirbek MA, Tannenholz L, Hen R (2012) NR2B-dependent plasticity of adult-born granule cells is necessary for context discrimination. J Neurosci 32:8696-8702. CrossRef Medline

Kuntziger T, Gavet O, Sobel A, Bornens M (2001) Differential effect of two stathmin/Op18 phosphorylation mutants on Xenopus embryo development. J Biol Chem 276:2297922984. CrossRef Medline

Martel G, Uchida S, Hevi C, Chévere-Torres I, Fuentes I, Park YJ, Hafeez H, Yamagata H, Watanabe Y, Shumyatsky GP (2016) Genetic demonstration of a role for stathmin in adult hippocampal neurogenesis, spinogenesis, and NMDA receptor-dependent memory. J Neurosci 36:1185-1202. CrossRef Medline

Shumyatsky GP, Malleret G, Shin RM, Takizawa S, Tully K, Tsvetkov E, Zakharenko SS, Joseph J, Vronskaya S, Yin D, Schubart UK, Kandel ER, Bolshakov VY (2005) stathmin, a gene enriched in the amygdala, controls both learned and innate fear. Cell 123:697-709. CrossRef Medline

Silva AJ, Kogan JH, Frankland PW, Kida S (1998) CREB and memory. Annu Rev Neurosci 21: 127-148. CrossRef Medline

Tashiro A, Sandler VM, Toni N, Zhao C, Gage FH (2006) NMDA-receptor-mediated, cellspecific integration of new neurons in adult dentate gyrus. Nature 442:929-933. CrossRef Medline

Trifilieff P, Herry C, Vanhoutte P, Caboche J, Desmedt A, Riedel G, Mons N, Micheau J (2006) Foreground contextual fear memory consolidation requires two independent phases of hippocampal ERK/CREB activation. Learn Mem 13:349-358. CrossRef Medline

Tsien JZ, Huerta PT, Tonegawa S (1996) The essential role of hippocampal CA1 NMDA receptor-dependent synaptic plasticity in spatial memory. Cell 87:1327-1338. CrossRef Medline

Uchida S, Martel G, Pavlowsky A, Takizawa S, Hevi C, Watanabe Y, Kandel ER, Alarcon JM, Shumyatsky GP (2014) Learning-induced and stathmin-dependent changes in microtubule stability are critical for memory and disrupted in ageing. Nat Commun 5:4389. CrossRef Medline

Vadodaria KC, Gage FH (2014) SnapShot: adult hippocampal neurogenesis. Cell 156:11141114.e1. CrossRef Medline 